\title{
Transgenic Bt cotton driven by the green tissue-specific promoter shows strong toxicity to lepidopteran pests and lower Bt toxin accumulation in seeds
}

\author{
Qing Wang ${ }^{\dagger}$, Yi Zhu ${ }^{\dagger}$, Lin Sun, Lebin Li, Shuangxia Jin* \& Xianlong Zhang \\ National Key Laboratory of Crop Genetic Improvement, Huazhong Agricultural University, Wuhan 430070, China
}

Received May 14, 2015; accepted July 20, 2015; published online December 30, 2015

\begin{abstract}
A promoter of the PNZIP (Pharbitis nil leucine zipper) gene $(1.459 \mathrm{~kb})$ was cloned from Pharbitis nil and fused to the GUS ( $\beta$-glucuronidase) and Bacillus thuringiensis endotoxin (Cry9C) genes. Several transgenic PNZIP::GUS and PNZIP::Cry9C cotton lines were developed by Agrobacterium-mediated transformation. Strong GUS staining was detected in the green tissues of the transgenic PNZIP::GUS cotton plants. In contrast, GUS staining in the reproductive structures such as petals, anther, and immature seeds of PNZIP::GUS cotton was very faint. Two transgenic PNZIP::Cry9C lines and one transgenic cauliflower mosaic virus (CaMV) 35S::Cry9C line were selected for enzyme-linked immunosorbent assay (ELISA) and insect bioassays. Expression of the Cry9C protein in the 35S::Cry9C line maintained a high level in most tissues ranging from 24.6 to $45.5 \mu \mathrm{g} \mathrm{g}^{-1}$ fresh weight. In green tissues such as the leaves, boll rinds, and bracts of the PNZIP::Cry9C line, the Cry9C protein accumulated up to 50.2, 39.7, and $48.3 \mu \mathrm{g} \mathrm{g}^{-1}$ fresh weight respectively. In contrast, seeds of the PNZIP::Cry9C line (PZ1.3) accumulated only $0.26 \mu \mathrm{g} \mathrm{g}^{-1}$ fresh weight of the Cry9C protein, which was 100 times lower than that recorded for the seeds of the CaMV 35S::Cry9C line. The insect bioassay showed that the transgenic PNZIP::Cry9C cotton plant exhibited strong resistance to both the cotton bollworm and the pink bollworm. The PNZIP promoter could effectively drive Bt toxin expression in green tissues of cotton and lower accumulated levels of the Bt protein in seeds. These features should allay public concerns about the safety of transgenic foods. We propose the future utility of PNZIP as an economical, environmentally friendly promoter in cotton biotechnology.
\end{abstract}

tissue-specific promoter, GUS expression, Bt toxin, transgenic cotton plants

Citation: Wang, Q., Zhu, Y., Sun, L., Li, L., Jin, S., and Zhang, X. (2016). Transgenic Bt cotton driven by the green tissue-specific promoter shows strong toxicity to lepidopteran pests and lower Bt toxin accumulation in seeds. Sci China Life Sci 59, 172-182. doi: 10.1007/s11427-015-4920-6

\section{INTRODUCTION}

The level and efficiency to which genes are expressed are mainly regulated by their cis-regulatory elements such as the promoters. Promoters are continually active within the cell are called constitutive promoters, whereas promoters become active in response to specific stimuli are called

$\dagger$ Contributed equally to this work

*Corresponding author (email: jsx@mail.hzau.edu.cn) inducible or tissue-specific promoters. Currently, the most widely used constitutive promoters include the rice actin, the maize ubiquitin, and the CaMV 35S promoters. Several other promoters have been isolated and identified from viruses and plants (Cazzonelli et al., 2005; Stavolone et al., 2003; Zhang et al., 2013). The constitutive expression of foreign genes could be toxic to their host plants, adversely affecting growth and development. For example, transgenic Bt cotton plants driven by the CaMV 35 S promoter, exhibit pleiotropic phenotypes, such as weaker vegetative growth and smaller cotton bolls, in comparison to wild plants. 
These pleiotropic phenotypes may be related to the exhaustion of too many assimilation products by the constitutive expression of foreign Bacillus thuringiensi (Bt) protein. Therefore, tissue-specific or inducible promoters would be more efficient and economical than constitutive promoters in such cases. Although many promoters have been isolated and tested in plant expression systems, only a few have been wildly used in agricultural biotechnology.

Genetically engineered cotton plants expressing the delta-endotoxin genes from Bacillus thuringiensis (Bt) offer an effective approach to the control of major lepidopteran pests (Helicoverpa armigera and Pectinophora gossypiella) and the reduction of pesticide dependence in China ( $\mathrm{Lu}$ et al., 2012; Wu et al., 2008). However, Bt cotton plants expressing the CrylA gene driven by the $35 \mathrm{~S}$ promoter of CaMV, have highlighted some performance deficiencies. The efficacy of the Cry1A endotoxin is not sustained across the growing season and declines as the crop matures in the field. The failure of the $35 \mathrm{~S}$ promoter is considered to be the reason for a reduction in the number of CrylA transcripts in post-squaring cotton (Olsen et al., 2005). Although it is expressed in most cell and tissue types, expression levels of the $35 \mathrm{~S}$ promoter are influenced by the physiology of cotton during development and environmental factors. The identification of other promoters that can drive strong expression levels throughout the growing season or of specific tissues that can function as substitutes for the $35 \mathrm{~S}$ promoter is necessary.

Chlorophyll plays a central role in photosynthesis, and chlorophyll biosynthesis has been studied extensively. MgP (Mg-protoporphyrin IX) monomethyl ester is converted to protochlorophyllide by the cyclase reaction in the biosynthesis pathway (Block et al., 2002; Von Wettstein et al., 1995). The PNZIP gene belongs to the leucine zipper gene family (Luan et al., 2013), and encodes a cyclase involved in this conversion in photosynthetically active mesophyll cells (Yang et al., 2009). The activity of the PNZIP promoter $(1,415 \mathrm{bp})$ has been confirmed to be nine times higher than that of the $35 \mathrm{~S}$ promoter in transgenic tobacco leaves, suggesting that this promoter could drive high-level expression of foreign genes in photosynthetic tissues (Yang et al., 2003).

Over the past two decades, transgenic Bt cotton has exhibited significant potential in pest control, especially for lepidopteran pests like the cotton bollworm. However, another lepidopteran species, the Spodoptera litura, was found to be resistant to Bt cotton harboring the CrylAc gene (Huang et al., 2005; Yu et al., 2003). Two transgenic cotton lines carrying the CrylAc gene were used for a $S$. litura bioassay, based on data obtained during the period 2002-2005 in the cotton planting region of the Yangtze River valley of China. The results showed that there was no significant difference in larval population densities between conventional fields and Bt cotton fields, suggesting low susceptibility of the $S$. litura larvae to Cry1Ac Bt cotton (Wan et al., 2008). S. litura is currently one of the major devastating pests in Cry1Ac Bt cotton fields, capable of consuming most leaves of the plant at the boll-setting stage and causing substantial yield reduction (Li et al., 2014). Recently, novel transgenic plants expressing the Bacillus thuringiensis $C r y 9 C$ gene have been generated through the incorporation of a gene stacking strategy (Li et al., 2014). Insect bioassays demonstrate that transgenic 35S::Cry9C cotton plants exhibit moderate toxicity to $H$. armigera, but strong toxicity to $S$. litura, in comparison to transgenic plants expressing the CrylAc gene. With the gene stacking strategy, the genes $C r y 9 C$ and $C r y 2 A$ or $C r y l A c$ are stacked by cross breeding. The F1 progenies from both Cry $9 C \times C r y 2 A$ and $C r y 9 C \times C r y l A c$ exhibit higher resistance to $S$. litura compared to their parents, suggesting the suitability of the Cry 9 C gene for S. litura control. The commercial application of this promising $B t$ gene was suspended however, because of the StarLink corn recalls in 2000 (Carter and Smith, 2007; Taylor and Tick, 2001). Since this recall, transgenic crops with the Cry9C gene have not been released for commercial use.

Cotton is a major crop in fiber production. In addition, cottonseed oil and cotton cake could be consumed by both humans and animals. Cottonseed is rich in protein (approximately 23\%) and oil (approximately 21\%) that are both of relatively high quality. Cotton currently ranks as one of the top five oil crops in China, just behind canola (oilseed rape), soybean, peanut, and sunflower. In the United States, cotton oil crops rank third in volume behind soybean and corn oils, and represent about $5 \%$ of the total domestic fat and oil supply (Small and Canada, 2009). The amount of protein present in global cottonseed output annually, can potentially provide the basic protein requirements of half a billion people (Palle et al., 2013). Reduced levels of foreign Bt protein accumulation in transgenic cotton seeds will to some extent allay public concerns about transgenic food. Previous studies have shown that considerable amounts of Bt protein can accumulate within cotton seeds (Dong and Li, 2007; Kranthi et al., 2005). For this purpose, a green-tissue specific promoter PNZIP was cloned from Pharbitis nil Choisy and fused to the GUS or Cry $9 \mathrm{C}$ genes. The transgenic cotton PNZIP::Cry9C line shows highly specialized expression patterns that promote its resistance to $S$. litura, as well as its safety as a vegetable oil or protein source for human consumption.

\section{RESULTS}

\section{Analysis of the cis-acting regulatory elements of the PNZIP promoter}

Two putative core prompter elements, the TATA-box (TATATA) and the CAAT-box (CAAT), and the translation start sites designated as +1 are indicated by boxes and arrowheads, respectively in Figure 1A. There were two putative light responsive elements, the GT1-motif and the 
3-AF1 binding site, which were located at positions -1282 and -868 from the transcription start site, respectively. In addition, two hormone response motifs, CGTCA and ABRE, which are involved in methyl jasmonate (MeJA) and abscisic acid responsiveness, were observed at positions -703 and -608 , respectively. The CAT-box is a cis-acting regulatory element related to meristem expression, located at position +69 . In addition, four GAAATA elements and two GATACT elements were found scattered along the PNZIP promoter sequence, suggesting that multiple putative motifs might regulate gene expression (Figure 1A).

\section{Molecular analysis of transgenic PNZIP::GUS and PNZIP::Cry9C cotton}

The three vectors that were constructed for genetic transformation are presented in Figure $1 \mathrm{~B}$ and the two cotton cultivars that were used for Agrobacterium-mediated transformation in this report. YZ-1 is an elite cultivar notably used in cotton transformation with the super-okra leaf. Y668 is a newly identified genotype with better agronomic traits than YZ-1. The hypocotyl cuts that were used as explants and co-cultured with Agrobacterium for $48 \mathrm{~h}$ at $21^{\circ} \mathrm{C}$ are illustrated in Figure 2A. The infected explants after transfer to the selection medium for callus induction, somatic embryogenesis, and plant regeneration are presented in Figure 2B-2E, respectively. The total numbers of PNZIP::GUS and PNZIP::Cry9C regenerated plants transferred to the greenhouse for further growth were 32 and 27 , respectively. The cotton cultivar YZ-1 has a typical super-okra leaf phenotype (Figure $2 \mathrm{~F}$ ), which is evidently different from the typical upland cotton leaves of Y668

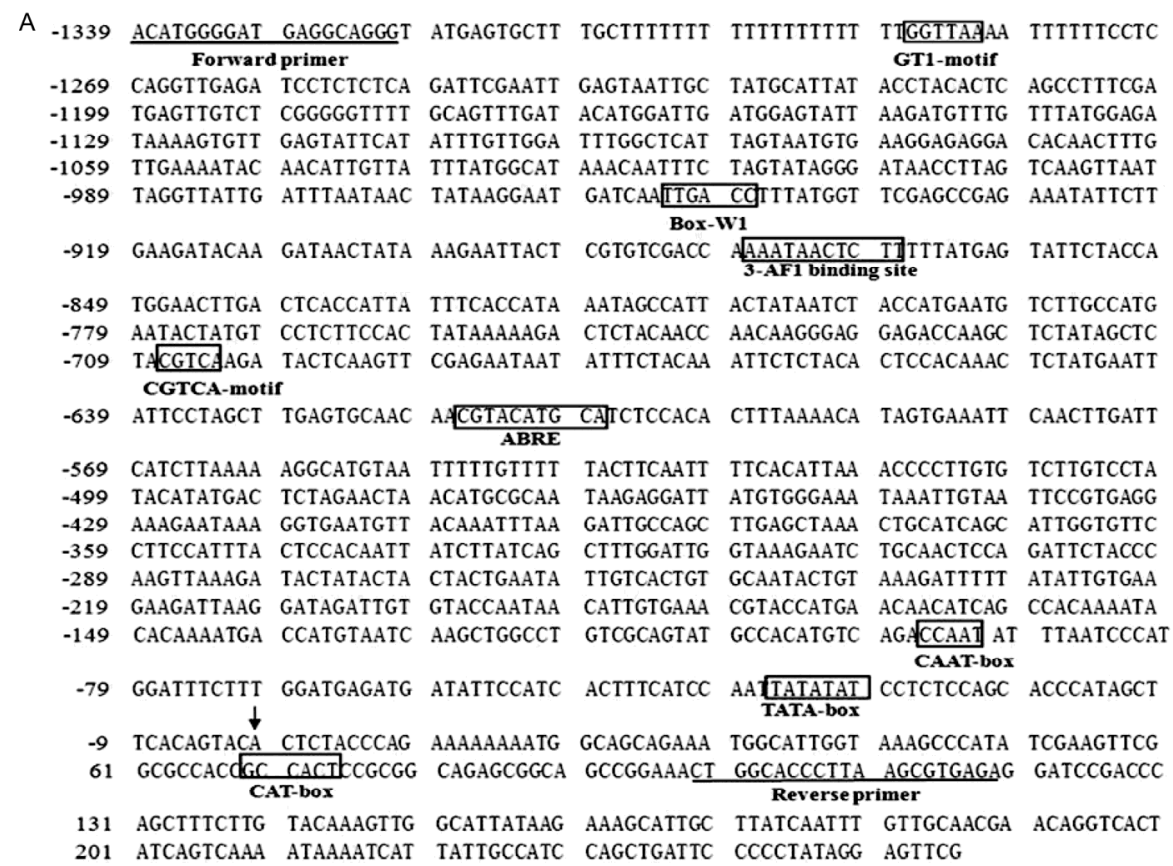

B $\quad$ PPNZIP ::GUS

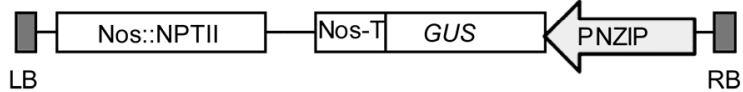

P35S::Cry9C
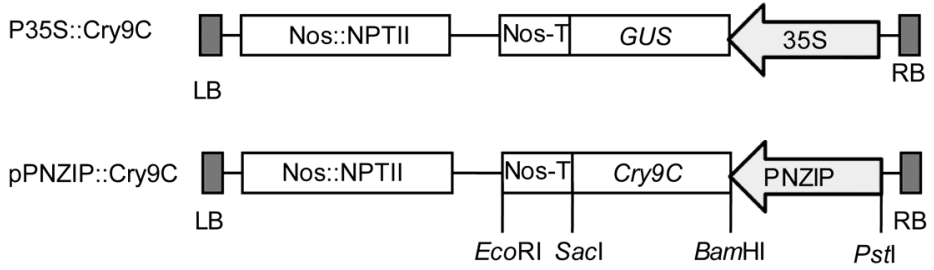

Figure 1 Prediction of cis-acting elements of the PNZIP prompter and schematic representation of T-DNA regions of plasmid vectors. A, GT1-motif: light responsive element; Box-W1: fungal elicitor responsive element; 3-AF1 binding site: light responsive element; CGTCA-motif: cis-acting regulatory element involved in methyl jasmonate (MeJA)-responsiveness; ABRE: cis-acting element involved in abscisic acid responsiveness; CAAT-box: common cis-acting element in promoter and enhancer regions; TATA-box: core promoter element around $30 \mathrm{bp}$ of transcription start; CAT-box: cis-acting regulatory element related to meristem expression. B, All vectors constructed based on the pCAMBIA3301 vector. LB: left border of T-DNA; RB: right border of T-DNA; 35S: cauliflower mosaic virus 35S promoter; PNZIP: Pharbitis nil leucine zipper promoter; Nos-T: nopaline synthase terminator; NPTII: neomycin phosphotransferase II gene. 


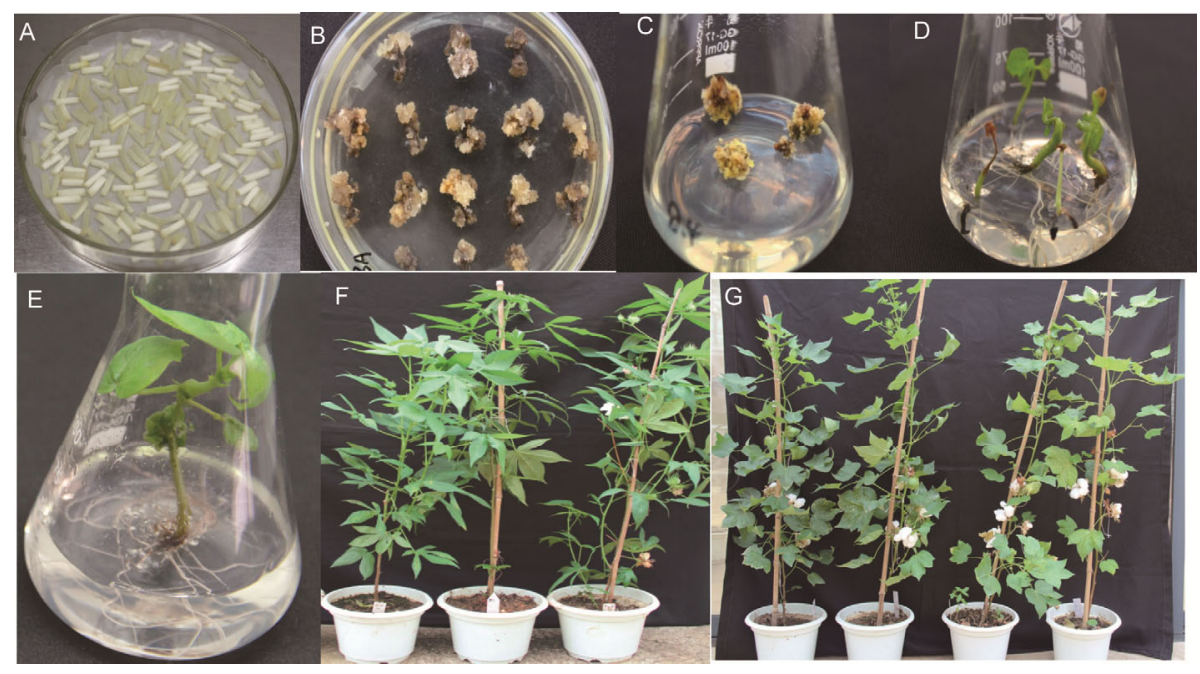

Figure 2 Agrobacterium-mediated genetic transformation and plant regeneration with PNZIP::GUS or PNZIP::Cry9C vector. A, Cotton hypocotyl segments co-cultured with Agrobacterium. B, Kanamycin resistant callus on selection medium. C, Embryogenic callus formation. D, Somatic embryo germination and plant regeneration. F, T0 PNZIP::GUS YZ-1 plants with unique super-okra leaf grown in pots. G, T0 PNZIP::Cry9C Y668 plants cultivated in a greenhouse.

plants shown in Figure 2G. Four positive transgenic lines (two plants from each line), namely PZ2, PZ3, PZ4, and PZ5 were confirmed by PCR analysis. Southern blot analysis further confirmed the integration of foreign GUS genes into the cotton genome and all four transgenic lines harbored a single T-DNA insertion (Figure 3A and 3C). PCR analysis for PNZIP::Cry9C T0 plants is presented in Figure 3B. Seven PNZIP::Cry9C lines were positive and used to generate T1 progeny for further analysis. Segregation of the NPTII gene in seven transgenic PNZIP::Cry9C T1 lines was detected by the kanamycin resistance test. Transgenic plants had very strong, healthy root systems with main and branch roots. However, the null plants had short, weak main roots with barely any branch roots. In the $\mathrm{T} 1$ population of the transgenic line-2.4, the total number of T1 plants screened in the kanamycin-medium and checked by PCR was 21 . The root phenotypes exhibited 16 plants with strong root systems and 5 plants with weak roots (Figure 4A). PCR data revealed that the phenotypes with strong roots were the only PCR positive plants (Figure 4B). PCR data were based on root phenotype, suggesting that antibiotic selection described in the present study is an effective method for the primary screening of transgenic progeny. Seven PNZIP:: GUS lines were screened by antibiotic selection and the results are summarized in Figure 4C. Six out of seven lines had a single T-DNA insertion based on the segregation ratio and these lines were used for further insect bioassays.

\section{Specific GUS expression pattern in transgenic PNZIP::GUS cotton lines}

GUS staining was only observed in tobacco leaves, suggesting the effectiveness of the PNZIP::GUS vector (Figure 5A). The PNZIP::GUS vector was then introduced into
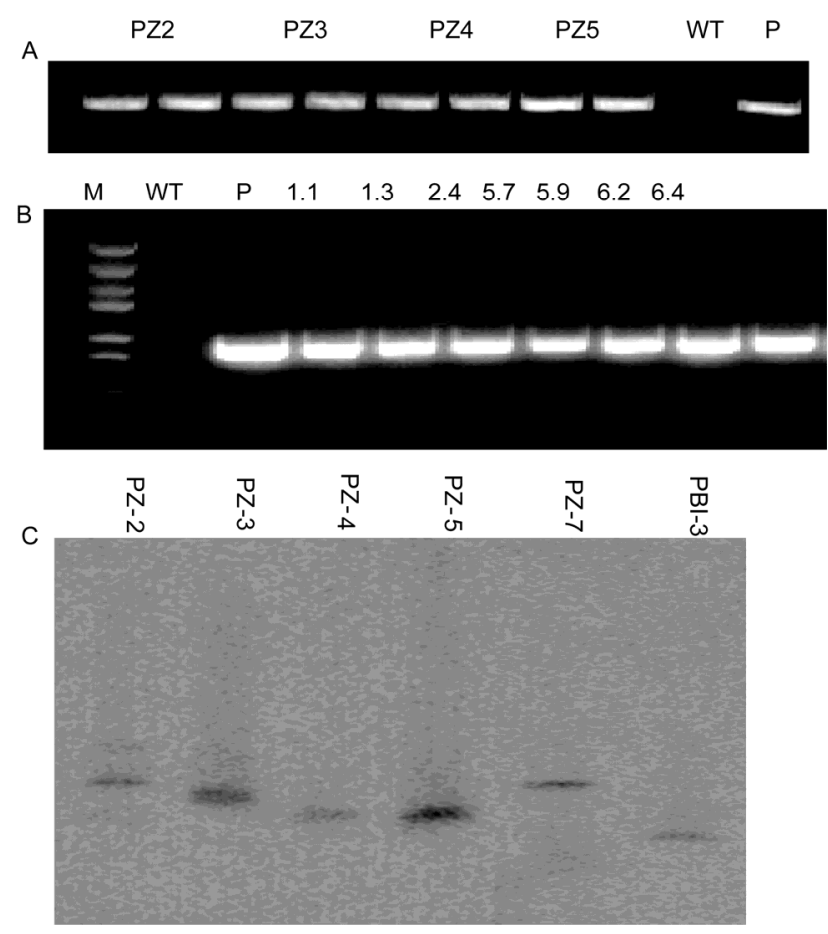

Figure 3 PCR and Southern blot analysis of putative transgenic cotton plants. A, T1 plants from four transgenic PNZIP::GUS lines: PZ2, PZ3, PZ4, and PZ5 (two plants per line). Null plant: negative control; P: positive control. B, T0 plants from transgenic PNZIP::Cry9C lines. C, Southern blot analysis for four transgenic PNZIP::GUS lines and one transgenic 35S::GUS line -PBI-3.

cotton genome by Agrobacterium -mediated transformation. The GUS expression pattern in transgenic PNZIP::GUS cotton seedlings, following introduction to the cotton genome by Agrobacterium-mediated transformation, was similar to that in transgenic tobacco lines and GUS staining was strongly localized only in cotton leaves (Figure 5B). GUS 


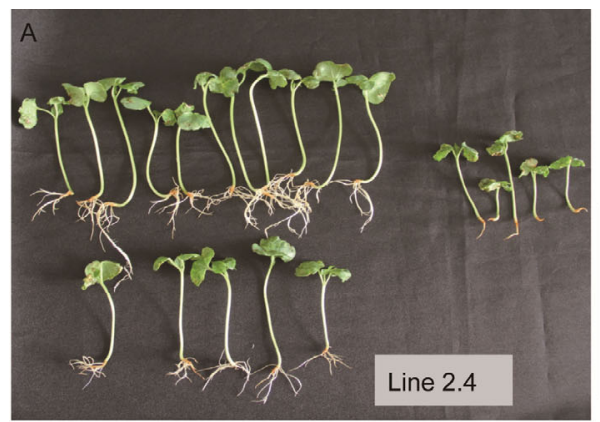

B

C

\begin{tabular}{cccccc}
\hline $\begin{array}{c}\text { Transgenic } \\
\text { PNZIP.:Cry 9C } \\
\text { lines }\end{array}$ & $\begin{array}{c}\text { No. of T0 } \\
\text { seeds tested }\end{array}$ & $\begin{array}{c}\text { No. of Kan } \\
\text { positive }\end{array}$ & $\begin{array}{c}\text { No. of Kan } \\
\text { negative }\end{array}$ & $\begin{array}{c}\text { Expected } \\
\text { ratio }\end{array}$ & $\begin{array}{c}\text { Value of chi-square } \\
\left(\chi^{2}\right)\end{array}$ \\
\hline 1.1 & 36 & 26 & 10 & $3: 1$ & $0.04^{*}$ \\
1.3 & 32 & 28 & 4 & $3: 1$ & $2.04^{*}$ \\
2.4 & 21 & 16 & 5 & $3: 1$ & $0.06^{*}$ \\
5.7 & 24 & 15 & 9 & $3: 1$ & $1.39^{*}$ \\
5.9 & 36 & 34 & 2 & $3: 1$ & 6.25 \\
6.2 & 42 & 34 & 8 & $3: 1$ & $0.18^{*}$ \\
6.4 & 30 & 24 & 6 & $3: 1$ & $0.4^{*}$ \\
\hline
\end{tabular}

Figure 4 Segregation of NPTII gene in transgenic PNZIP::Cry9C T1 progeny of eight transgenic lines revealed by the kanamycin resistance test. A, Twenty-one T1 seeds of the PNZIP::GUS line-2.4 geminated on half-MS medium supplemented with $100 \mathrm{mg} \mathrm{L}^{-1}$ kanamycin for 10 d. Geminated seedlings were screened to identify genuine transgenic progeny based on root growth. B, PCR analysis of 21 plantlets showed 16 PCR positive and 5 PCR negative plants. PCR data were based on root phenotype. C, Number of kanamycin resistant and non-resistant seedlings based on antibiotic selection. Segregation ratio was determined by chi-square analysis. *: Not significantly different from an expected ratio at the 0.05 level of significance $\left(\chi^{2} 0.05=3.84\right)$.

expression patterns in mature transgenic cotton plants were also detected in both 35S::GUS and PNZIP::GUS transgenic lines. Strong GUS staining was detected in most green tissues including the leaves and cotton boll shells of transgenic cotton when GUS was driven by the PNZIP promoter. However, GUS staining in reproductive tissues of PNZIP:: GUS cotton, such as the petals, anther, and embryo was very faint (Figure 5C-5F). In 35S::GUS transgenic cotton, strong GUS staining was observed in most tissues, including petals, anther, and immature embryos (Figure $5 \mathrm{C}-5 \mathrm{~F}$ ).

\section{GUS activity in green tissues of transgenic PNZIP::GUS cotton}

GUS activity determined by the MUG/MU method is presented in Figure 6. Six tissues/organs of transgenic 35S::GUS and PNZIP::GUS plants were evaluated for GUS activity. In non-photosynthetic tissues/organs, including the seeds, roots, petals, and anther, GUS activity of PNZIP:: GUS plants was significantly lower than in 35S::GUS plants (Figure 6). GUS activity in the seeds of the transgenic

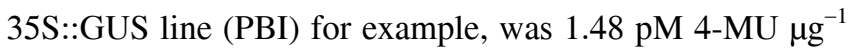
total protein $\mathrm{min}^{-1}$, which was 10 times higher than that in the PNZIP::GUS line, PZ7 (0.14) (Figure 6A). Similarly, GUS activity in the roots of the PBI line was 9.8, but was almost undetectable in PZ7 transgenic lines (Figure 6B). GUS activity in the petals and anthers of PBI lines showed similar trends as in the seeds and roots. However, GUS ac- tivity in the green boll rinds of the PZ7 line was comparable to that of the PBI line. In the leaves of both PZ7 and PBI lines, GUS activity levels were similar (Figure 6C and 6D).

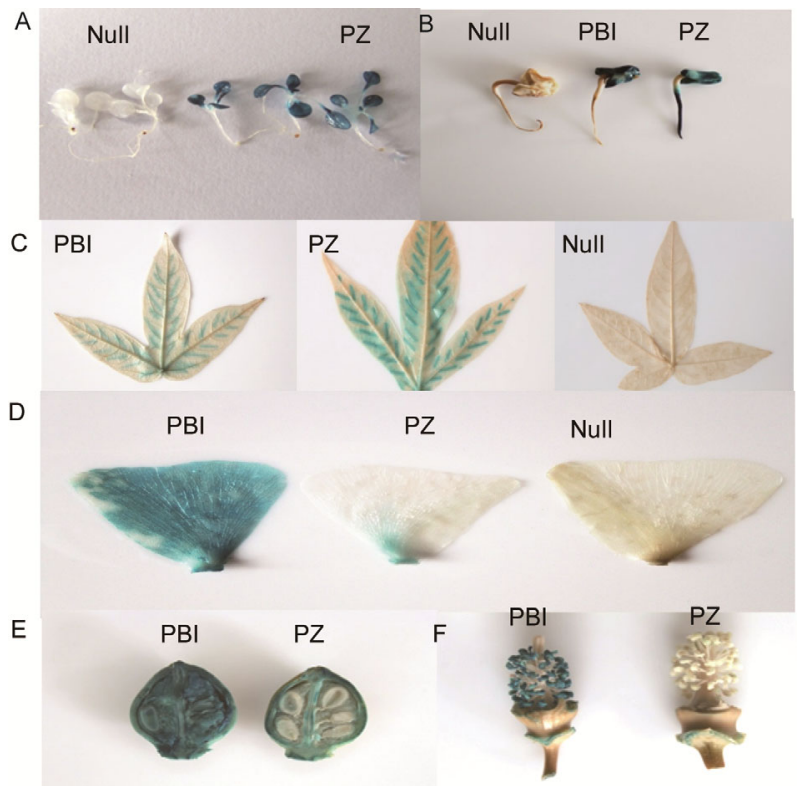

Figure 5 GUS staining of PNZIP::GUS and 35S::GUS transgenic tobacco and cotton seedlings. PZ: PNZIP::GUS transgenic plants; PBI: 35S::GUS transgenic plants. Null plants were used as the negative control. A, GUS staining for tobacco young plantlets. B, GUS staining for cotton seedlings. C, GUS staining for cotton leaves. D, GUS staining for cotton petals. E, GUS staining for dissecting cotton bolls. F, GUS staining for cotton anthers and stigma. 

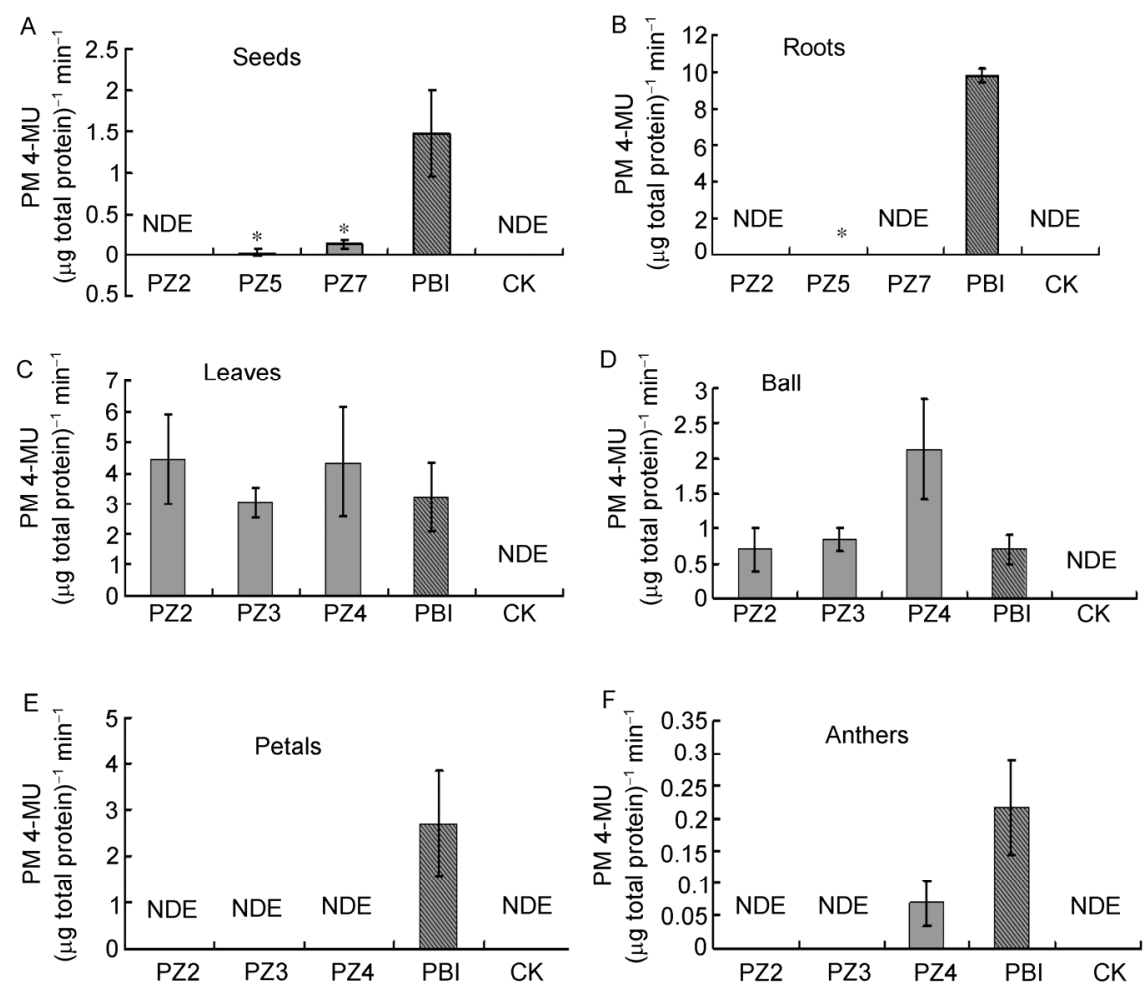

Figure 6 Detection of GUS activity in various tissues and organs of transgenic 35S::GUS and PNZIP::GUS cotton plants. PZ: PNZIP::GUS transgenic plants; PBI: 35S::GUS transgenic plants. Null plants were used as the negative control. A, Detection of the GUS activity in cotton seeds. B, Detection of the GUS activity in cotton roots. C, Detection of the GUS activity in cotton leaves. D, Detection of the GUS activity in cotton bolls. E, Detection of the GUS activity in cotton petals. F, Detection of the GUS activity in cotton anthers. Bar graphs represent average GUS activity \pm SD of three replicates. *: Denotes significant differences $(P<0.05)$; NDE: non detectable.

High Cry9C accumulation in green tissues and undetectable accumulation in seeds of transgenic PNZIP:: Cry9C cotton

The $\mathrm{T} 1$ progeny segregation ratios of six lines were $3: 1$, suggesting a single T-DNA insertion. Two transgenic PNZIP::Cry9C lines (with one T-DNA copy) PZ1.3 and PZ6.4 were selected for ELISA and insect bioassays. The previously developed transgenic Cry9C cotton driven by the CaMV 35S promoter was used as a positive control in the ELISA and insect bioassays. The Cry $9 \mathrm{C}$ protein content in eight tissues/organs of transgenic 35S::Cry9C, PNZIP:: Cry9C, and null lines was detected by ELISA. Expression of the Cry9C protein maintained high levels in all tissues/organs of 35S::Cry9C plants ranging from 24.6 to $45.5 \mu \mathrm{g} \mathrm{g}^{-1}$ fresh weight. However, the expression level of Cry9C in transgenic PNZIP::Cry9C showed strong tissue/organ specificity. In the green tissues/organs such as leaves, boll rinds, and bracts, Cry9C accumulated up to levels of 50.2, 39.7, and $48.3 \mu \mathrm{g} \mathrm{g}^{-1}$ fresh weight, respectively. In seeds of the PZ1.3 line, the Cry9C protein measured only $0.26 \mu \mathrm{g} \mathrm{g}^{-1}$ fresh weight, which was 100 -fold lower than its accumulation in seeds of the 35S::Cry9C line. Expression levels of Cry9C in other non-photosynthetic tissues such as the roots, petals, and anthers of the PNZIP::Cry9C line were also significantly lower than those in corresponding tis- sues/organs of the 35S::Cry9C line were (Figure 7). There was no significant difference between the accumulation of Cry 9C protein in the young leaves of PNZIP::Cry9C and 35S::GUS. However, significantly higher levels of the Cry9C protein accumulated in senescent leaves of the PNZIP::Cry9C line than in those of the 35S::Cry9C line (Figure 7).

\section{Transgenic PNZIP::Cry9C cotton and its resistance to the cotton bollworm and pink bollworm}

The cotton bollworm $(H$. armigera) and pink bollworm $(P$. gossypiella) are two of the most destructive insect species to cotton production. The results of three insect bioassays with these two insect species are presented in Figure 8. In the first experiment, the cotton bollworm larvae were fed with transgenic cotton leaves for $6 \mathrm{~d}$ and the extent of leaf damage and larvae mortality rates were recorded. When fed null cotton leaves, the larvae could consume a considerable number of leaves (Figure 8A); however, larvae consumed significantly less PNZIP::Cry9C leaves (Figure 8A-1). Mortality rates of larvae fed null cotton leaves were also significantly lower than those of groups fed transgenic 35S:: Cry9C or PNZIP::Cry9C leaves. Two transgenic PNZIP:: Cry9C lines, PZ1.3 and PZ 6.4, and the 35S::Cry9C line yielded similar insect mortality rates (Figure 8A-2). In the 


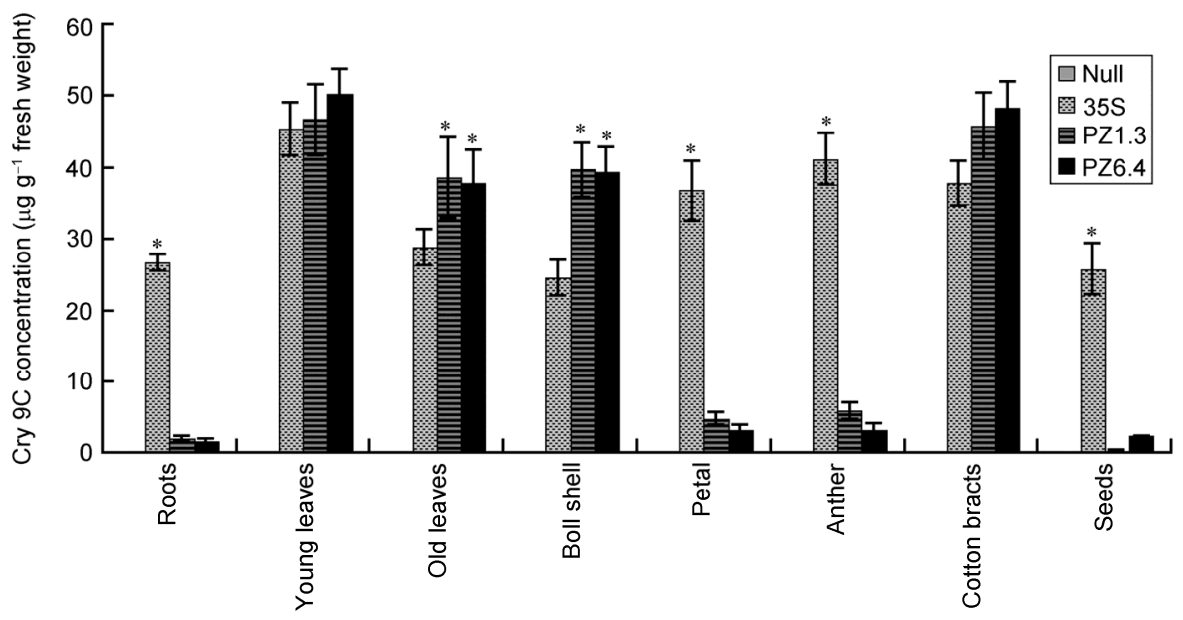

Figure 7 Cry9C concentration detection in various tissues and organs of 35S::Cry9C and PNZIP::Cry9C transgenic lines by ELISA. Bar graphs represent average GUS activity \pm SD of three replicates. *: Denotes significant differences $(P<0.05)$; NDE: non detectable.
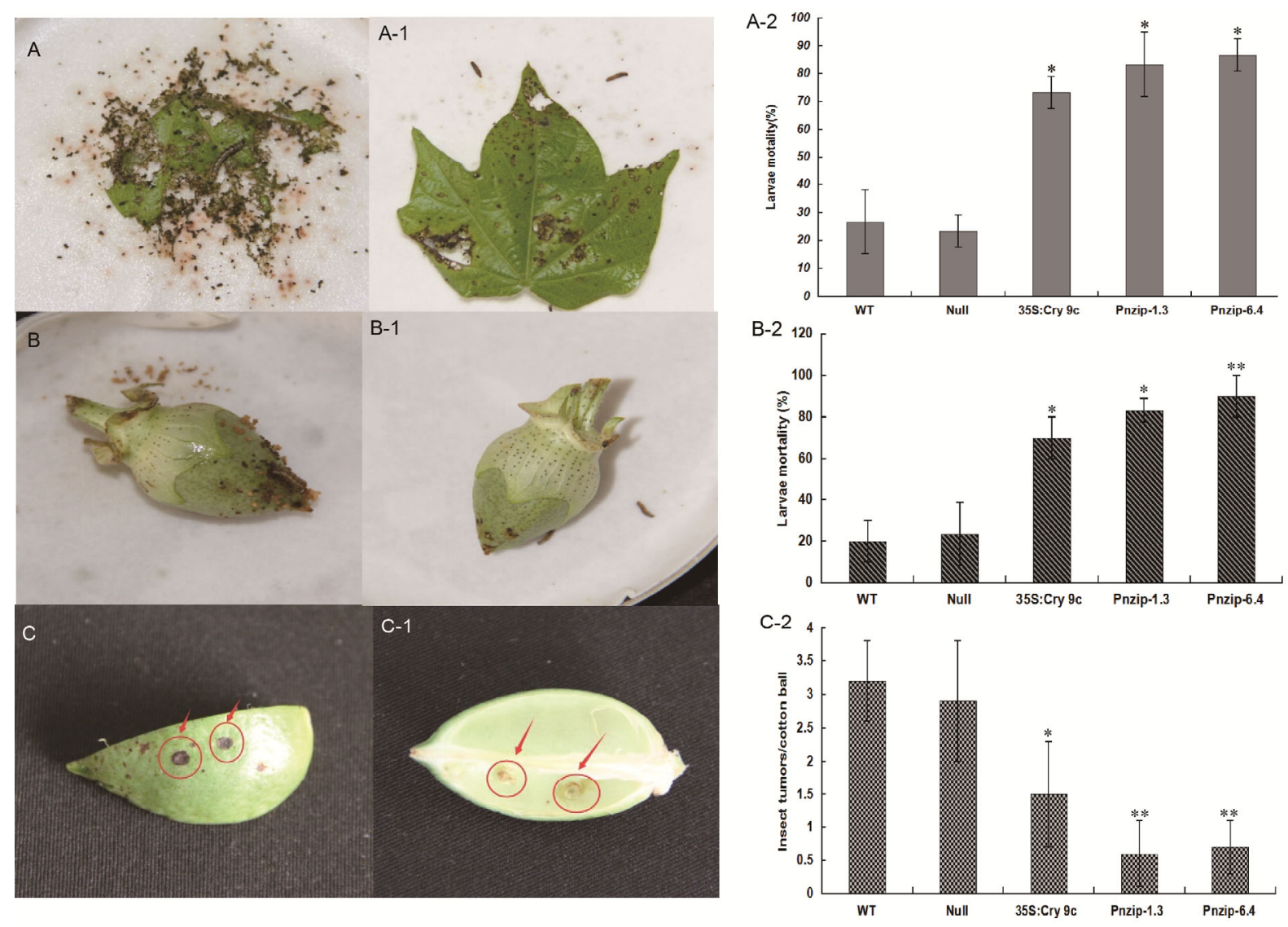

Figure 8 Insect bioassay of transgenic 35S::Cry9C and PNZIP::Cry9C lines with the cotton bollworm and pink cotton bollworm. A, Cotton bollworm fed the wild-type cotton leaf. A-1: Cotton bollworm fed transgenic PNZIP::Cry9C cotton leaf; A-2: Quantitative data of insect bioassay with cotton bollworm. B, Pink cotton bollworm fed the wild-type cotton boll. B-1: Pink cotton bollworm fed PNZIP::Cry9C cotton boll; B-2: Quantitative data of insect bioassay with pink cotton bollworm. C, Scars on the surface of wild-type cotton boll after being fed to pink cotton bollworm insects. C-1: The insect galls/tumors inside the cotton boll two weeks after infestation by the pink cotton bollworm; C-2: Quantifying insect galls/tumors within cotton bolls after infestation by the pink cotton bollworm.

second insect bioassay, cotton bollworm larvae were fed young cotton bolls from null and transgenic plants. The results showed that most larvae could penetrate the null cotton boll shells and enter the boll (Figure 8B). However, most larvae failed to penetrate the shells of transgenic PNZIP:: Cry9C lines and died in their attempts to overcome the bar- 
rier (Figure 8B-1). After feeding on young bolls, insect mortality rates in transgenic 35S::Cry9C or PNZIP::Cry9C lines were significantly higher than that in the null line (Figure 8B-2). In the third insect bioassay, five first-instar larvae were released to the bracts and fed on 10-day-old cotton bolls of greenhouse plants. Two weeks later, the bolls were split and the extent of insect gall production in the entire boll was recorded. In Figure $8 \mathrm{C}$ and $8 \mathrm{C}-1$, the scars on the surface of the boll shell and the insect galls within the boll are evident. Quantitative data revealed that total galls in the transgenic PNZIP::Cry9C and 35S::Cry9C lines were significantly lower $(P<0.01$ and $P<0.05$, respectively) than that in the wild-type (WT) and null lines. Among the transgenic lines, two PNZIP::Cry9C lines had significantly lower numbers of galls $(P<0.05)$ than the 35S::Cry9C line (Figure 8C-2).

\section{DISCUSSION}

Most commercial transgenic $\mathrm{Bt}$ cotton hybrids currently available have descended from a common parent, "Monsanto-531", with a single T-DNA insertion, which was obtained via Agrobacterium tumefaciens transformation. The plastid vector for this transformation contains a CrylAc gene driven by a $35 \mathrm{~S}$ promoter that enables the production of the Cry1Ac protein in almost all parts of the plant (Perlak et al., 2001). The $35 \mathrm{~S}$ promoter is by far the most widely used promoter in plant transformation, especially for dicotyledonous plant species, including cotton (Dutt et al., 2014; Porto et al., 2014). When transferred to plants, this promoter is capable of driving high levels of gene expression in most plant tissues/organs. The $35 \mathrm{~S}$ promoter was identified by Benfey and his colleagues more than two decades ago (Benfey and Chua, 1990; Benfey et al., 1989) and has been studied extensively to identify key cis-regulatory sequences that provide high levels of gene expression. DNA sequence analyses reveal the presence of two major domains, A and $\mathrm{B}$, that include several subdomains in the $35 \mathrm{~S}$ promoter (Benfey et al., 1990). Abundant cis-regulatory sequences and combinations make this promoter very efficient at plant development. The $35 \mathrm{~S}$ promoter is therefore considered useful for constitutive gene expression. Several studies, however, have revealed that varied expression levels can result from the interaction of this promoter with various physiological stages of plant growth as well as environmental factors. Low levels of GUS activity, driven by the CaMV 35S promoter, have also been reported in tobacco pollen (Twell et al., 1989; Wilkinson et al., 1997). In these cases, the expression of this promoter were several times lower than the expression of pollen-specific promoters (Twell et al., 1989). In other studies, no $35 \mathrm{~S}$ promoter expression was detected in the mature pollen of petunia (Mascarenhas and Hamilton, 1992; van der Leede-Plegt et al., 1992) and Arabidopsis plants (Wilkinson et al., 1997).
The temporal and spatial control of Bt toxin expression in Bollgard transgenic cotton has been extensively reported in China, India, USA, and Australia (Bakhsh et al., 2010; Benedict et al., 1996; Dong and Li, 2007; Greenplate et al., 2001; Kranthi et al., 2005; Mahon et al., 2002). Cry1Ac toxin expression in Bollgard cotton after the flowering stage, has shown a significant decrease in efficacy against insects (Fitt et al., 1998; Greenplate et al., 1998). The expression of Cry1Ac among cultivars can vary up to twofold throughout the growing season (Adamczyk and Meredith, 2004). For most commercialized Bt cotton varieties, relatively higher Bt toxin levels are expressed in the early growing season, but significantly decline during the late season (Greenplate et al., 2000; Greenplate, 1999; Xia et al., 2004). The expression of Bt protein also varies in different parts of the cotton plant. In the fully expanded leaves, Bt protein content was highest compared to the roots, stems, and petioles during the seedling stage. In the flowering parts, ovaries accumulated significantly higher toxin protein levels than pistils and stamens during anthesis (Chen et al., 2000). A more recent study revealed that expression levels of both Cry1Ac and Cry2A toxins varied among cotton lines and between different plant organs/tissues (Bakhsh et al., 2010). In that study, researchers found maximal expression levels of Cry1Ac and Cry2A in the leaves of Bt cotton, followed by the squares, bolls, anthers, petals, and fruit (Bakhsh et al., 2010). Previous studies have suggested that the 35S promoter is a developmental promoter. Research of this promoter has triggered further research to identify new potential promoters, that can facilitate both consistent expression of insecticidal genes throughout the life of the cotton plant, and tissue specific expression of the Bt toxin aimed at lepidopteran insects as the primary target.

Compared to the $35 \mathrm{~S}$ promoter, the PNZIP promoter shows tissue-specific expression patterns that are highly expressed in photosynthetic tissues, such as leaves and green stems, but minimally expressed in non-photosynthetic tissues, such as roots, seeds, and flowering parts. The tissue-specific expression pattern of PNZIP is mainly attributed to its unique cis-acting regulatory elements. Previous studies have demonstrated that the PNZIP promoter drives gene expression for chlorophyll biosynthesis in higher plants, and that analysis of the cis-acting regulatory elements suggest the regulation of gene expression by multiple motifs (Yang et al., 2009; Zheng et al., 1998). Notably, among these motifs were two putative light responsive elements, the GT1-motif and the 3-AF1 binding site, which may be responsible for the photosynthetic tissue-specific expression of the PNZIP promoter. GUS expression patterns in both transgenic PNZIP::GUS tobacco and cotton revealed strong expression in leaves and green cotton bolls, but weak to no expression in roots, seeds, and floral organs of cotton plants. Similarly, the Cry9C toxin driven by the PNZIP promoter was highly accumulated in green tissues such as the leaves and green bolls, but showed minimal levels in 
seeds of the transgenic PNZIP::Cry9C cotton plants. In addition to the comparisons drawn between tobacco and cotton species, the present study also tested the feasibility of the PNZIP promoter for use against the genetic background of cotton cultivars. For this purpose, two cotton cultivars YZ-1 and Y668 were successfully transformed with the PNZIP::GUS and PNZIP::Cry9C genes, respectively. YZ-1 is an elite cotton cultivar identified in 2006 (Jin et al., 2006) and widely used in cotton genetic transformation (Deng et al., 2012; Tang et al., 2014) for its superior transformation efficiency and shorter regeneration periods in comparison to Coker lines. Y668 is a recently identified elite cotton cultivar with comparable regenerability as that of YZ-1, and superior agronomic traits. In both YZ-1 and Y668 transgenic lines, expression of GUS and Cry9C, driven by the PNZIP promoter, exhibited green-tissue specific patterns.

The young bracts and boll rinds of the cotton plant were the primary and favorite targets of the pink cotton bollworm. Bt toxin accumulation in the boll rind of transgenic plants is usually lower when driven by the $35 \mathrm{~S}$ promoter (Kranthi et al., 2005). The pink cotton bollworm could therefore penetrate the boll rind and remain in immature bolls. Post-harvest, the pink bollworm larvae can be hidden within seeds for long periods, and could be easily transported through trade. In PNZIP::Cry9C plants, expression levels of Cry9C in the bracts and boll rinds were significantly higher than levels recorded in comparable parts of the 35S::Cry9C plants. Feeding experiments with leaves and young bolls revealed that higher expression levels of Cry9C exhibited strong toxicity to both cotton bollworms and pink bollworms. In the ball feeding bioassay particularly, most larvae died during penetration of the boll rinds, leaving behind the scars or insect galls either within, or on the outer surface of the shells.

The PNZIP promoter could efficiently drive Bt toxin expression in green tissues of transgenic cotton and induce low accumulation levels of foreign $\mathrm{Bt}$ protein in cotton seeds. The PNZIP promoter is therefore indicated for future use as a safe, economical promoter in the field of cotton biotechnology.

\section{MATERIALS AND METHODS}

\section{Vector construction and plant transformation}

The PNZIP promoter (GenBank accession No: AF373414.1, 1,459 bp in length) (Zheng et al., 1998) was amplified by PCR, from young leaves of Pharbitis nil Choisy using the primers P1: 5'- GGGGACAAGTTTGTACAAAAAAGCAGGCTGCATTGATCATTGCAGAAGCAC-3' and P2: 5'-GGGGACCACTTTGTACAAGAAAGCTGGGTCGCT ATTACTGCTTACTAGTACTATATGC-3'. The upstream attB1 adapter and downstream attB2 adapter primers are underlined in the primer sequences. The major cis-acting regulatory elements were analyzed by the PlantCARE tool (http://bioinformat-ics.psb.ugent.be/webtools/plantcare/html/) (Lescot et al., 2002). PNZIP promoter fragments were then fused with the GUS reporter gene in the plasmid pGWB433, by attB $\times$ attP(BP) and attL $\times$ attR(LR) reactions (Invitrogen, Carlsbad, USA). The pBI121 plasmid containing the 35S::GUS expression cassette was used in parallel experiments. The terminator fragment of the nopaline synthase (NOS) gene (Nos-T) was retrieved from pBI121, digested by restriction endonucleases $S a c \mathrm{I}$ and EcoRI and subcloned into the pCAMBIA 2300 vector. The open reading fream (ORF) fragment of the Cry $9 \mathrm{C}$ gene was ligated into Bam$\mathrm{HI} / \mathrm{SacI}$ sites of modified pCAMBIA2300 (named pC2300-9C). The PNZIP promoter was amplified by PCR from the pGWB433 vector containing PNZIP::GUS with the primers: P3 (5'-TCTCTGCAGACATGGGGATGAGGCAGGG-3') and P4 (5'-ACAGGATCCTCTCACGCTTAAGGGTGCCAG-3'). The restriction sites PstI and BamHI are both underlined in the P3 and P4 sequences, respectively. The promoter fragments were inserted into the Pst $/$ Bam HI sites of pCAMBIA2300-9C, resulting in the pPNZIP:: Cry9C plasmid. We first tested the pPNZIP::Cry9C vector in tobacco via Agrobacterium tumefaciens-mediated transformation. The two vectors were then introduced to two Gossypium hirsutum cultivars, YZ1 and Y668 by Agrobacterium tumefaciens-mediated transformation as previously described (Jin et al., 2005; Jin et al., 2006; Li et al., 2014).

\section{PCR and Southern blot analysis of the regenerated plants}

For PCR analysis, the GUS or NPTII gene specific primers were used in PCR analysis of the putative transgenic PNZIP::GUS and PNZIP::Cry 9C T1 plants. The null plant in the $\mathrm{T} 1$ population was used as the negative control and PNZIP::GUS plasmids were used as the positive control. The primers: 5'-GCAACTGGACAAGGCACTAGC-3' and 5'-AAATCGCCGCTTTGGACATA-3' were used for the GUS gene, and the primers: 5'-ACCAGTTCCTGCTGAACACC-3' and 5'-TACAGGCGCACGTCGTAGTA-3' were used for the $C r y 9 \mathrm{C}$ gene. Amplification consisted of pre-denaturation at $95^{\circ} \mathrm{C}$ for $5 \mathrm{~min}$; denaturation at $95^{\circ} \mathrm{C}$ for $30 \mathrm{~s}$; annealing at $56^{\circ} \mathrm{C}$ for $30 \mathrm{~s}$; extension at $72^{\circ} \mathrm{C}$ for $30 \mathrm{~s}-1 \mathrm{~min}$; and final extension at $72^{\circ} \mathrm{C}$ for $10 \mathrm{~min}$. PCR products were separated on a $1.0 \%$ agarose gel. For the Southern blot, genomic DNA was extracted from leaves $(200 \mathrm{mg}$ ) and $20 \mu \mathrm{g}$ DNA was digested with HindIII restriction enzymes for $48 \mathrm{~h}$. The DNA fragments were dispersed by electrophoresis, transformed into nylon membranes, and hybridized with a GUS probe, amplified from the plasmid vector ( $\mathrm{Li}$ et al., 2014).

\section{Segregation analysis of the $\mathrm{T} 1$ population from trans- genic PNZIP::Cry9C cotton by antibiotic analysis}

T1 seeds from five transgenic PNZIP::Cry9C lines $(2,4,5$, 
6, and 10) were geminated on 1/2 Murashige and Skoog (MS) medium supplemented with $50 \mathrm{mg} \mathrm{L}^{-1}$ kanamycin and incubated at $28^{\circ} \mathrm{C}$ for $10 \mathrm{~d}$. The geminated seedlings were screened to identify the genuine transgenic progeny based on root growth. The numbers of kanamycin resistant and non-resistant seedlings were recorded and chi-square analysis was performed to determine the segregation ratio.

\section{Histochemical GUS assays and quantitative analysis of GUS activity}

To identify the GUS expression pattern of 35S::GUS and PNZIP::GUS plants, various tissues/organs of the transgenic plants were stained for $5-6 \mathrm{~h}$ at $37^{\circ} \mathrm{C}$ in GUS staining buffer. The stained tissues were decolorized overnight at $37^{\circ} \mathrm{C}$ in $75 \%$ ethanol. GUS activity in plant tissues/organs was measured by the use of 4-methylumbelliferyl- $\beta$-D-glucuronide (4-MUG) as a substrate to create the fluorescent substance 4-methylumbelliferone (4-MU). MU content was measured by a fluorescence spectrophotometer at a wavelength of $456 \mathrm{~nm}$. Three biological replicates were performed.

\section{Quantitative analysis of Cry9C protein by ELISA}

Cry9C protein content in transgenic plants was quantified by the methods outlined in our previous study ( $\mathrm{Li}$ et al., 2014) using the ELISA QuantiPlate ${ }^{\mathrm{TM}}$ kit (EnviroLogix, Portland, USA). Crude protein was extracted from the tissues/organs of transgenic 35S::Cry9C and PNZIP::Cry9C cotton plants, measured according to the Bradford protocol, and diluted to 500- to 1,500-fold according to the concentration of the total protein. The optimal concentration of total soluble Cry9C protein was quantified by the ELISA kit following the manufacturer protocol. Three biological replicates were performed.

\section{Insect bioassay of transgenic PNZIP::Cry9C cotton plants}

Insect eggs and larvae of the cotton bollworm (H. armigera) were provided by Prof. Niu Changying from the College of Plant Science and Technology of Huazhong Agriculture University. The pink bollworm ( $P$. gossypiella) eggs were collected from the research station on the campus of Huazhong Agriculture University. The eggs of both species were hatched on an artificial diet at $28^{\circ} \mathrm{C}$ under a photoperiod of $14 \mathrm{~h}$ light/10 $\mathrm{h}$ dark. The $\mathrm{T} 1$ generation of PNZIP::Cry9C and negative/positive control plants was used in the insect bioassays. For the cotton bollworm bioassay, the fully expanded young cotton leaves were fed to 10 first-instar larvae in an incubator at $28^{\circ} \mathrm{C}$ under $14 \mathrm{~h}$ light/10 h dark for $6 \mathrm{~d}$. Leaf damage and insect mortality were assessed.

For the pink bollworm bioassay, young cotton bolls
(10-15 $\mathrm{mm}$ in diameter) were fed to five first-instar larvae (five insect larvae per boll) in planta for $2 \mathrm{~d}$. Boll damage and insect growth were recorded $15 \mathrm{~d}$ after feeding. Three biological replicates were performed for each bioassay.

Acknowledgments This work was supported by the National Natural Science Foundation of China (31171592, 31371673), and Fundamental Research Funds for the Central Universities (2013PY064).

Adamczyk, J., and Meredith, W. (2004). Genetic basis for variability of Cry1Ac expression among commercial transgenic Bacillus thuringiensis $(\mathrm{Bt})$ cotton cultivars in the United States. J Cotton Sci 8, 17-23.

Bakhsh, A., Rao, A.Q., Shahid, A.A., Husnain, T., and Riazuddin, S. (2010). CaMV $35 \mathrm{~S}$ is a developmental promoter being temporal and spatial in expression pattern of insecticidal genes (crylac \& cry $2 a)$ in cotton. Aust J Basic Appl Sci 4, 37-44.

Benedict, J., Sachs, E., Altman, D., Deaton, W., Kohel, R., Ring, D., and Berberich, S. (1996). Field performance of cottons expressing transgenic CryIA insecticidal proteins for resistance to Heliothis virescens and Helicoverpa zea (Lepidoptera: Noctuidae). J Econ Entomol 89, 230-238.

Benfey, P.N., and Chua, N.H. (1990). The cauliflower mosaic virus 35S promoter: combinatorial regulation of transcription in plants. Science 250, 959-966.

Benfey, P.N., Ren, L., and Chua, N.H. (1990). Combinatorial and synergistic properties of CaMV $35 \mathrm{~S}$ enhancer subdomains. EMBO J 9, 1685.

Benfey, P.N., Ren, L., and Chua, N.H. (1989). The CaMV 35S enhancer contains at least two domains which can confer different developmental and tissue-specific expression patterns. EMBO J 8, 2195.

Block, M.A., Tewari, A.K., Albrieux, C., Maréchal, E., and Joyard, J. (2002). The plant S-adenosyl-1-methionine: Mg-protoporphyrin IX methyltransferase is located in both envelope and thylakoid chloroplast membranes. Eur J Biochem 269, 240-248.

Carter, C.A., and Smith, A. (2007). Estimating the market effect of a food scare: the case of genetically modified StarLink corn. Rev Econ Stat $89,522-533$.

Cazzonelli, C.I., McCallum, E.J., Lee, R., and Botella, J.R. (2005). Characterization of a strong, constitutive mung bean (Vigna radiata L.) promoter with a complex mode of regulation in planta. Transgenic Res 14, 941-967.

Chen, S., Wu, J., Zhou, B., Huang, J., and Zhang, R. (2000). On the temporal and spatial expression of Bt toxin protein in Bt transgenic cotton. Acta Gossypii Sin 12, 189-193.

Deng, F., Tu, L., Tan, J., Li, Y., Nie, Y., and Zhang, X. (2012). GbPDF1 is involved in cotton fiber initiation via the core cis-element HDZIP2ATATHB2. Plant Physiol 158, 890-904.

Dong, H., and Li, W. (2007). Variability of endotoxin expression in Bt transgenic cotton. J Agron Crop Sci 193, 21-29.

Dutt, M., Dhekney, S.A., Soriano, L., Kandel, R., and Grosser, J.W. (2014). Temporal and spatial control of gene expression in horticultural crops. Horticul Res 1, 14047.

Fitt, G., Daly, J., Mares, C., and Olsen, K. (1998). Changing efficacy of transgenic Bt cotton-patterns and consequences. In: 6th Australisian Applied Entomological Research Conference, University of Queensland, Brisbane 189-196.

Greenplate, J., Head, G., and Penn, S. (1998). Factors potentially influencing the survival of Helicoverpa zea on Bollgard cotton. In: Proceedings of Beltwide Cotton Conferences, Maryland and Washington.

Greenplate, J., Mullins, W., Penn, S., and Embry, K. (2001). Cry1Ac Bollgard ${ }^{\circledR}$ varieties as influenced by environment, variety and plant age: 1999 gene equivalency field studies. In: Proceedings of the Beltwide cotton conference, Memphis 790-793.

Greenplate, J., Penn, S., Mullins, J.W., Oppenhuizen, M., Dugger, P., and 
Richter, D. (2000). Seasonal Cry1Ac levels in DP50B: the "Bollgard ${ }^{\circledR}$ basis" for Bollgard II. In: 2000 Proceedings Beltwide Cotton Conferences, San Antonio, 4-8 January, National Cotton Council 2, 1039-1040.

Greenplate, J.T. (1999). Quantification of Bacillus thuringiensis insect control protein Cry1Ac over time in Bollgard cotton fruit and terminals. J Econ Entomol 92, 1377-1383.

Han, J., Tan, J., Tu, L., and Zhang, X. (2014). A peptide hormone gene, GhPSK promotes fibre elongation and contributes to longer and finer cotton fibre. Plant Biotechnol J 12, 861-871.

Hu, L., Yang, X., Yuan, D., Zeng, F., and Zhang, X. (2011). GhHmgB3 deficiency deregulates proliferation and differentiation of cells during somatic embryogenesis in cotton. Plant Biotechnol J 9, 1038-1048.

Huang, D., Liu, H., and Jiang, S. (2005). Effects of Zhongmiansuo 45 and Zhongmiansuo 41 on experimental population of Spodoptera litura. Acta Phytophyl Sin 33, 1-5.

Jin, S., Zhang, X., Liang, S., Nie, Y., Guo, X., and Huang, C. (2005). Factors affecting stable transformation and plant regeneration during transforming embryogenic callus of Upland cotton (Gossypium hirsutum L.) via Agrobacterium tumefaciens. Plant Cell Tiss Org Cult $81,229-237$.

Jin, S., Zhang, X., Nie, Y., Guo, X., Liang, S., and Zhu, H. (2006). Identification of a novel elite genotype for in vitro culture and genetic transformation of cotton. Biologia Plantarum 50, 519-524.

Jin, S., Liu, G., Zhu, H., Yang, X., and Zhang, X. (2012). Transformation of upland cotton (Gossypium hirsutum L.) with GFP gene as a visual marker. J Int Agr 11, 910-919.

Kranthi, K.R., Naidu, S., Dhawad, C., Tatwawadi, A., Mate, K., Patil, E., Bharose, A., Behere, G., Wadaskar, R., and Kranthi, S. (2005). Temporal and intra-plant variability of Cry1Ac expression in Bt-cotton and its influence on the survival of the cotton bollworm, Helicoverpa armigera (Hubner) (Noctuidae: Lepidoptera). Currentence 89, 291-298.

Lescot, M., Déhais, P., Thijs, G., Marchal, K., Moreau, Y., Van de Peer, Y., Rouzé, P., and Rombauts, S. (2002). PlantCARE, a database of plant $c i s$-acting regulatory elements and a portal to tools for in silico analysis of promoter sequences. Nucleic Acids Res 30, 325-327.

Li, F., Fan, G., Wang, K., Sun, F., Yuan, Y., Song, G., Li, Q., Ma, Z., Lu, C., and Zou, C. (2014). Genome sequence of the cultivated cotton Gossypium arboreum. Nat Genetics 46, 567-572.

Li, L., Zhu, Y., Jin, S., and Zhang, X. (2014). Pyramiding Bt genes for increasing resistance of cotton to two major lepidopteran pests: Spodoptera litura and Heliothis armigera. Acta Physiol Plant 36, 2717-2727.

Liu, G., Li, X., Jin, S., Liu, X., Zhu, L., Nie, Y., and Zhang, X. (2014). Overexpression of rice NAC gene SNACl improves drought and salt tolerance by enhancing root development and reducing transpiration rate in transgenic cotton. PLoS One 9, e86895.

Lu, Y., Wu, K., Jiang, Y., Guo, Y., and Desneux, N. (2012). Widespread adoption of $\mathrm{Bt}$ cotton and insecticide decrease promotes biocontrol services. Nature 487, 362-3675.

Luan, W., Shen, A., Jin, Z., Song, S., Li, Z., and Sha, A. (2013). Knockdown of OsHox33, a member of the class III homeodomain-leucine zipper gene family, accelerates leaf senescence in rice. Sci China Life Sci 56, 1113-1123.

Mahon, R., Finnergan, J., Olsen, K., and Lawrence, L. (2002). Environmental stress and the efficacy of Bt cotton. Aust Cotton Grower 23, 18-21.

Mascarenhas, J.P., and Hamilton, D.A. (1992). Artifacts in the localization of GUS activity in anothers of petunia transformed with a CaMV 35S-GUS construct. Plant J 2, 405-408.

Min, L., Zhu, L., Tu, L., Deng, F., Yuan, D., and Zhang, X. (2013). Cotton GhCKI disrupts normal male reproduction by delaying tapetum programmed cell death via inactivating starch synthase. Plant $\mathbf{J} 75$, 823-835.

Olsen, K., Daly, J., Finnegan, E., and Mahon, R. (2005). Changes in Cry1Ac Bt transgenic cotton in response to two environmental factors: temperature and insect damage. J Econ Entomol 98, 1382-1390.

Palle, S.R., Campbell, L.M., Pandeya, D., Puckhaber, L., Tollack, L.K., Marcel, S., Sundaram, S., Stipanovic, R.D., Wedegaertner, T.C., and Hinze, L. (2013). RNAi-mediated Ultra-low gossypol cottonseed trait: performance of transgenic lines under field conditions. Plant Biotechnol J 11, 296-304.

Perlak, F.J., Oppenhuizen, M., Gustafson, K., Voth, R., Sivasupramaniam, S., Heering, D., Carey, B., Ihrig, R.A., and Roberts, J.K. (2001). Development and commercial use of Bollgard ${ }^{\circledR}$ cotton in the USA-early promises versus today's reality. Plant J 27, 489-501.

Porto, M.S., Pinheiro, M.P.N., Batista, V.G.L., dos Santos, R.C., de Albuquerque, Melo, Filho, P., and de Lima, L.M. (2014). Plant promoters: an approach of structure and function. Mol Biotechnol 56, 38-49.

Small, E., and Canada, Cndrd. (2009). Top 100 Food Plants. Ottawa: NRC Research Press.

Stavolone, L., Kononova, M., Pauli, S., Ragozzino, A., de Haan, P., Milligan, S., Lawton, K., and Hohn, T. (2003). Cestrum yellow leaf curling virus (CmYLCV) promoter: a new strong constitutive promoter for heterologous gene expression in a wide variety of crops. Plant Mol Biol 53, 703-713.

Tang, W., Tu, L., Yang, X., Tan, J., Deng, F., Hao, J., Guo, K., Lindsey, K., and Zhang, X. (2014). The calcium sensor GhCaM7 promotes cotton fiber elongation by modulating reactive oxygen species (ROS) production. New Phytol 202, 509-520.

Taylor, M.R., and Tick, J.S. (2001). The StarLink case: Issues for the future. Washington: Resources for the Future Press.

Twell, D., Klein, T.M., Fromm, M.E., and McCormick, S. (1989). Transient expression of chimeric genes delivered into pollen by microprojectile bombardment. Plant Physiol 91, 1270-1274.

van der Leede-Plegt, L.M., van de Ven, B.C., Bino, R.J., van der Salm, T.P., and van Tunen, A.J. (1992). Introduction and differential use of various promoters in pollen grains of Nicotiana glutinosa and Lilium longiflorum. Plant Cell Rep 11, 20-24.

Von Wettstein, D., Gough, S., and Kannangara, C.G. (1995). Chlorophyll biosynthesis. Plant Cell 7, 1039.

Wan, P., Wu, K., Huang, M., Yu, D., and Wu, J. (2008). Population dynamics of Spodoptera litura (Lepidoptera: Noctuidae) on Bt cotton in the Yangtze River Valley of China. Environ Entomol 37, 1043-1048.

Wilkinson, J.E., Twell, D., and Lindsey, K. (1997). Activities of CaMV $35 \mathrm{~S}$ and nos promoters in pollen: implications for field release of transgenic plants. J Exp Bot 48, 265-275.

Wu, K., Lu, Y., Feng, H., Jiang, Y., and Zhao, J. (2008). Suppression of cotton bollworm in multiple crops in China in areas with Bt toxin-containing cotton. Science 321, 1676-1678.

Xia, L., Xu, Q., and Guo, S. (2004). BT insecticidal gene and its temporal expression in transgenic cotton plants. Zuo Wu Xue Bao 31, 197-202.

Yang, Y., Yang, G., Liu, S., Guo, X., and Zheng, C. (2003). Isolation and functional analysis of a strong specific promoter in photosynthetic tissues. Sci China C Life Sci 46, 651-660.

Yang, Y., Yu, Y., Yang, G., Zhang, J., and Zheng, C. (2009). Tissue-specific expression of the PNZIP promoter is mediated by combinatorial interaction of different cis-elements and a novel transcriptional factor. Nucleic Acids Res 37, 2630-2644.

Yu, Y., Kang, X., Lu, Y., Liang, J., Wang, H., Wu, J., and Yang, Y. (2003). Effects of the transgenic Bt cotton on the increase in population of Podoptera litura Fabricius. Jiangsu J Agr Sci 20, $169-172$.

Zhang, S., Lian, Y., Liu, Y., Wang, X., Liu, Y., and Wang, G. (2013). Characterization of a maize Wip1 promoter in transgenic plants. Int $\mathrm{J}$ Mol Sci 14, 23872-23892.

Zheng, C., Porat, R., Lu, P., and O'Neill, S.D. (1998). PNZIP is a novel mesophyll-specific cDNA that is regulated by phytochrome and a circadian rhythm and encodes a protein with a leucine zipper motif. Plant Physiol 116, 27-35.

Open Access This article is distributed under the terms of the Creative Commons Attribution License which permits any use, distribution, and reproduction in any medium, provided the original author(s) and source are credited. 